\title{
Stacking Breath
}

National Cancer Institute

\section{Source}

National Cancer Institute. Stacking Breath. NCI Thesaurus. Code C50752.

Condition where there are a greater number of inhalations relative to the number of exhalations. 